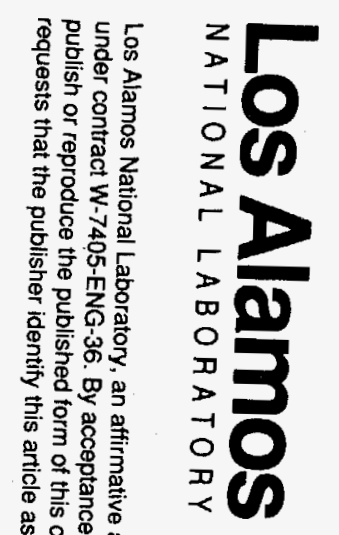



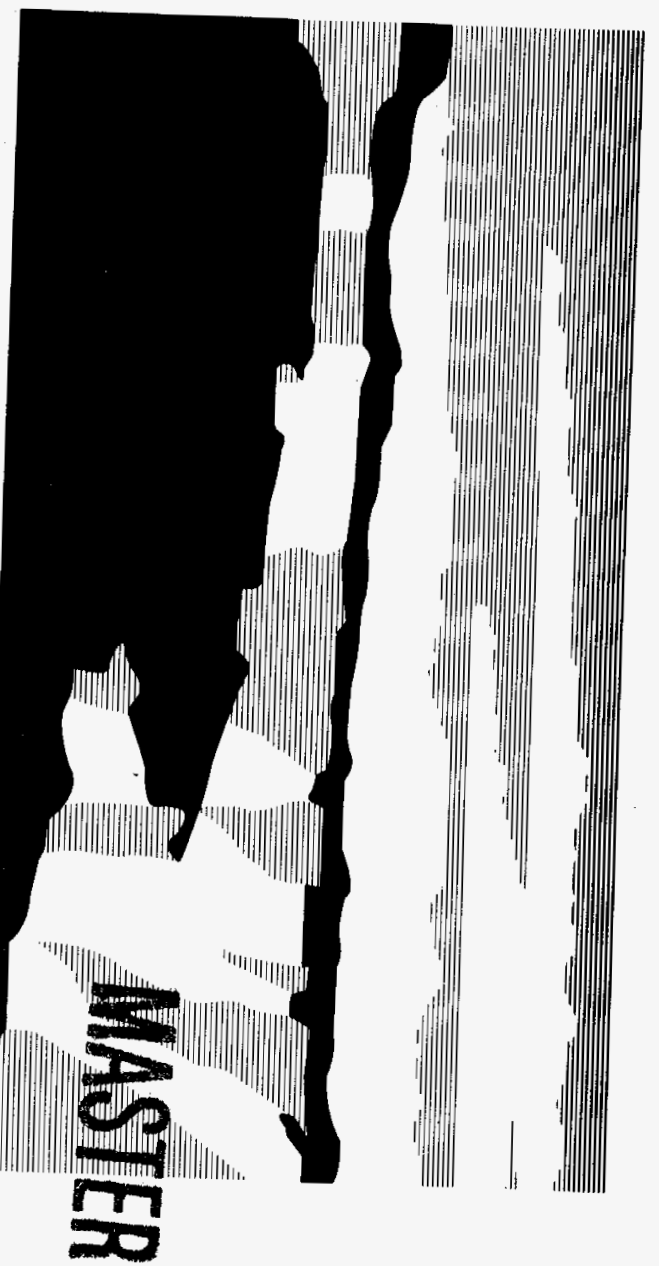

This report was prepared as an account of work sponsored by an agency of the United States Government. Neither the United States Government nor any agency thereof, nor any of their employees, makes any warranty, express or implied, or assumes any legal liability or responsibility for the accuracy, completeness, or usefulness of any information, apparatus, product, or process disclosed, or represents that its use would not infringe privately owned rights. Referpree berein to any specific commercial product, process, or service by trade name, trademark, manufacturer, or otherwise does not necessarily constitute or imply its endorsement, recommendation, or favoring by the United States Government or any agency thereof. The views and opinions of authors expressed herein do not necessarily state or reflect those of the United States Government or any agency thereo

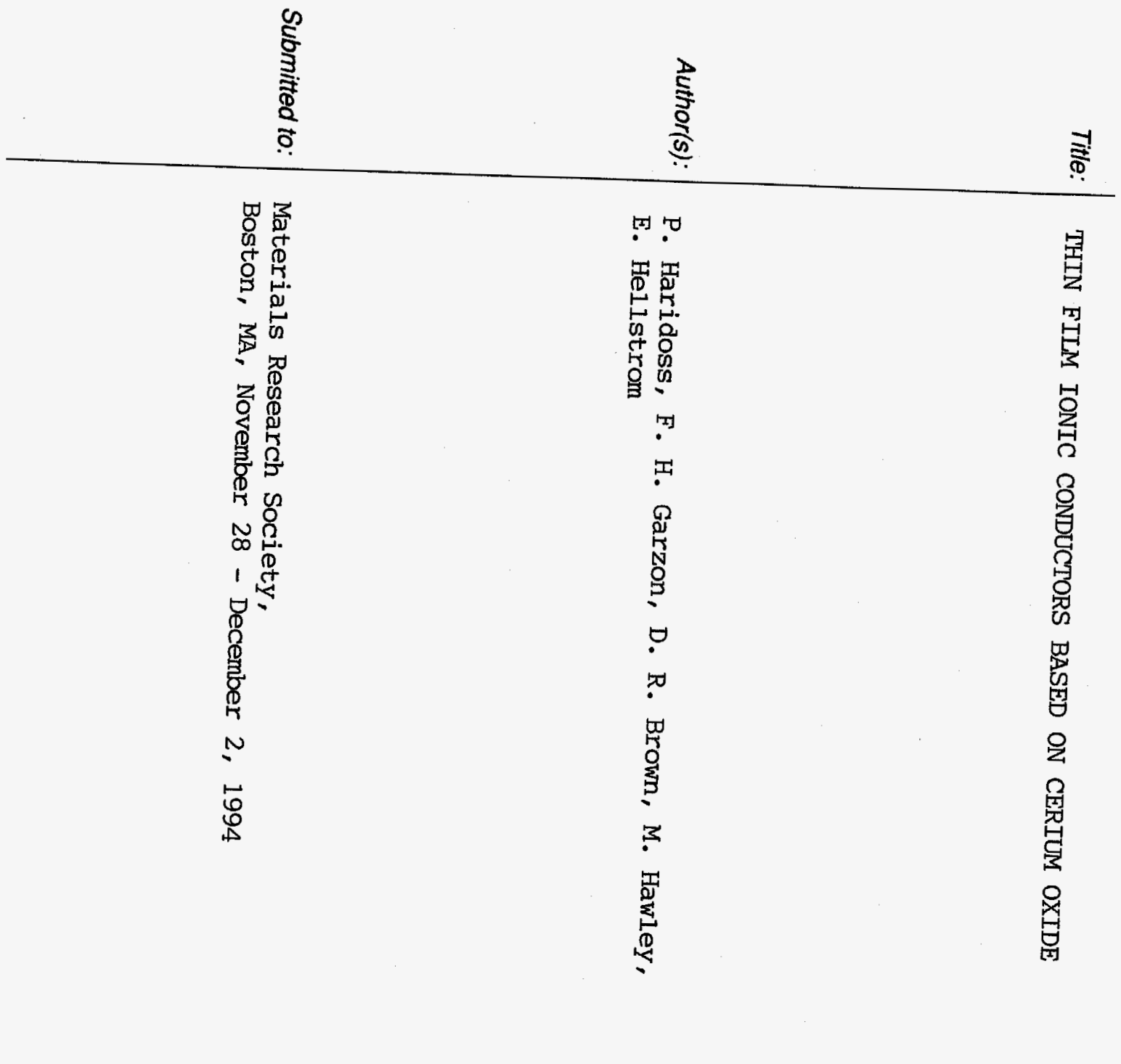




\section{DISCLAIMER}

Portions of this document may be illegible in electronic image products. Images are produced from the best available original document. 


\title{
THIN FILM IONIC CONDUCTORS BASED ON CERIUM OXIDE
}

\author{
PRATHAP HARIDOSS*, FERNANDO H. GARZON, DAVID R. BROWN, MARILYN \\ HAWLEY AND ERIC HELLSTROM*. \\ Los Alamos National Laboratory, Los Alamos, N.M. 87545 \\ ${ }^{*}$ University of Wisconsin-Madison, WI. 53706
}

\begin{abstract}
Fluorite and perovskite structure cerium oxide based ceramics are a class of materials that may exhibit good oxygen ion and/or protonic conductivity. We have successfully deposited thin films of these materials on a variety of substrates. Interesting orientation relationships were noticed between cerium oxide films and strontium titanate bi-crystal substrates. Near lattice site coincidence theory has been used to study these relationships.
\end{abstract}

\section{INTRODUCTION}

Knowledge of orientation relationships between thin films and substrates is very useful for fabricating devices 1,2 . For example YBCO rotates $45^{\circ}$ in the $a-b$ plane when deposited on cerium oxide and this has been used for fabricating biepitaxial Josephson junctions. We have studied the orientation relationship between a strontium titanate bi-crystal and a cerium oxide film deposited on it. We observed $8^{\circ}$ of rotation between the film and the substrate that does not seem to have been observed before. We explain this rotation using coincident site lattice theory.

\section{EXPERIMENTAL PROCEDURE}

The strontium titanate bi-crystal substrate was obtained from Shinkosha Co., Ltd. Tokyo, Japan. The bi-crystal had (010) planes parallel to the surface and the [100] directions made $36.8^{\circ}$ $+/-1^{0}$ with each other across the boundary. One side of the substrate had been polished to a surface roughness of $+/-15 \mathrm{~nm}$.

$\mathrm{CeO}_{2}$ thin films were electron beam evaporated from a bulk $\mathrm{CeO}_{2}$ source (International Advanced materials) using a CVA Tennescal electron beam evaporation system operated at 2.5 $\mathrm{KV}, 100 \mathrm{~mA}$ of beam current. The electron beam eventually reduces the cerium oxide source and thus requires fresh source material after each deposition. The base pressure was maintained at $1 \times 10^{-5}$ torr by leaking oxygen into the deposition system. The substrates were mounted on a tantalum plate with silver paste and heated during deposition by a pyrolytic graphite boron nitride heater (Union Carbide). Deposition temperatures were monitored by a thermocouple mounted on the tantalum plate. Thin films were deposited at temperatures from 600 to $800{ }^{\circ} \mathrm{C}$ on $\mathrm{r}$ plane $(1 \overline{1} 02)$ sapphire and were deposited at $715^{\circ} \mathrm{C}$ on strontium titanate.

$\mathrm{X}$-ray phi scans and theta - 2 theta scans were used to determine the orientation relationship between the film and the substrate. We also used X-ray theta-2 theta scans to determine the phase purity and orientation of the material deposited.

\section{RESULTS AND DISCUSSION}

Figure 1 displays typical $\emptyset$ - $2 \varnothing$ scans for $\mathrm{CeO}_{2}$ films deposited on a variety of substrates. The maximum temperature for material deposition $\left(750^{\circ} \mathrm{C}\right)$ was determined by the appearance of 


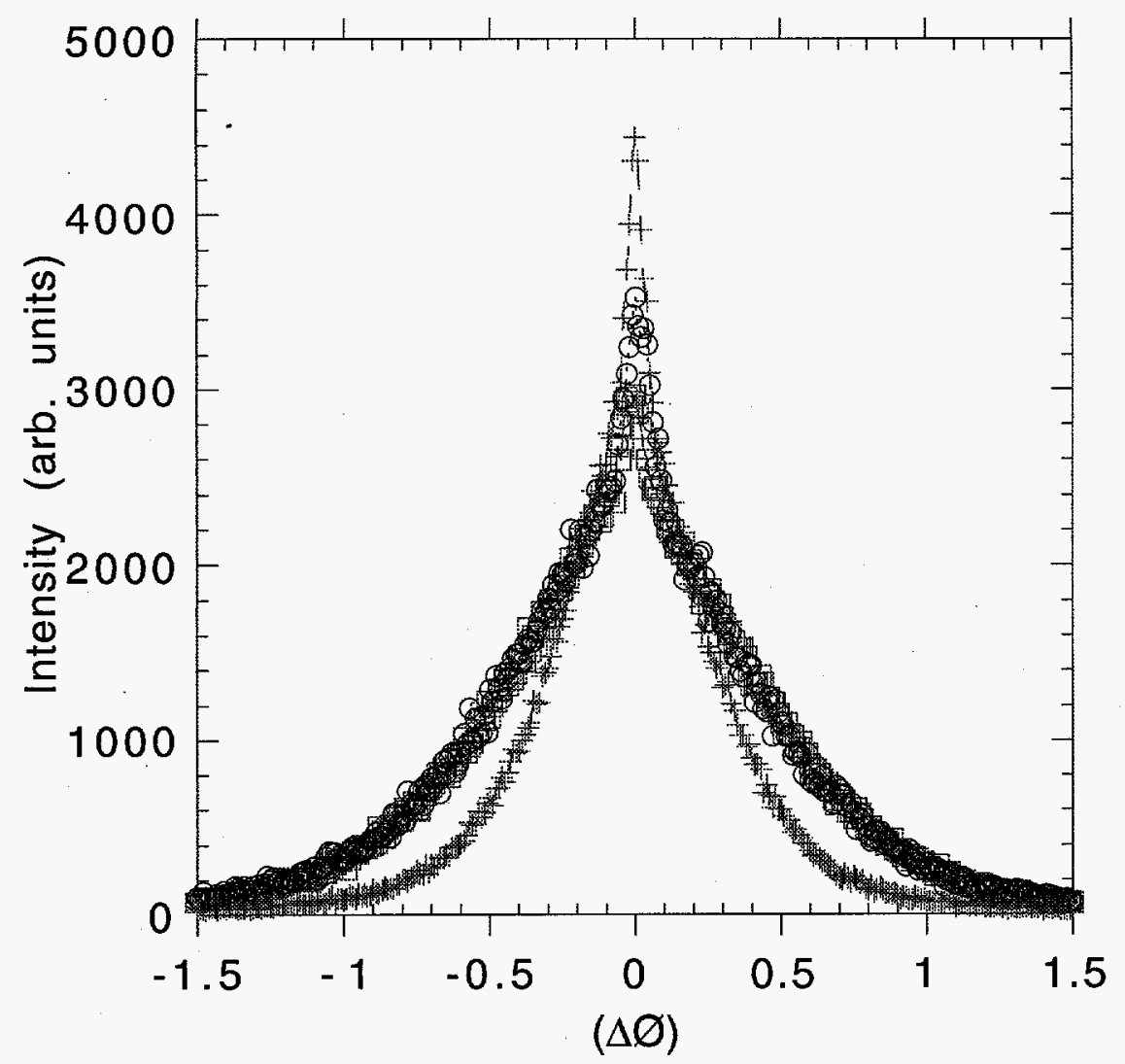

FIG. 1. X-ray rocking curves of cerium oxide films evaporated on r-plane sapphire substrates. The square, circle and cross symbols represent data for films deposited at 700,720 and $750{ }^{\circ} \mathrm{C}$ respectively

(111) oriented material. The $\mathrm{X}$-ray rocking curve FWHMs for $\mathrm{CeO}_{2}$ deposited on r-plane sapphire improved substantially with increasing growth temperature. Figure 1 displays this improvement in crystallinity with deposition temperature.

On overlaying the $\mathrm{x}$-ray phi scans taken to locate 330 poles of the strontium titanate substrate and the 440 poles of the cerium oxide film it, was seen that the film had rotated about $8^{\circ}$ with respect to the substrate. This is shown in Figure 2. The cerium oxide bi-crystal film was therefore oriented at about $52^{\circ}$. Strontium titanate has a lattice parameter of $3.9051 \mathrm{~A}^{\circ}$ and cerium oxide has a lattice parameter of $5.4110 \mathrm{~A}^{\mathrm{O}}$. We have been able to explain this rotation of $8^{\circ}$ by aligning the [310] direction of strontium titanate with the [210] of cerium oxide. This alignment causes the appearance of a coincident site lattice where in the $\Sigma 10$ boundary of strontium titanate coincides with the $\Sigma 5$ boundary of cerium oxide. This coincident site lattice is shown in Figure 3 . In this figure we have superimposed (200) of strontium titanate on (400) of cerium oxide. These planes have a high concentration of oxygen atoms. As can be seen, at the vertices of the coincident site lattice the oxygen atoms overlap whereas within the lattice they are spread wide apart. This arrangement may be the driving force for the $8^{\circ}$ rotation that we have observed. This also appears to be a fairly stable configuration in view of the low angle involved. 


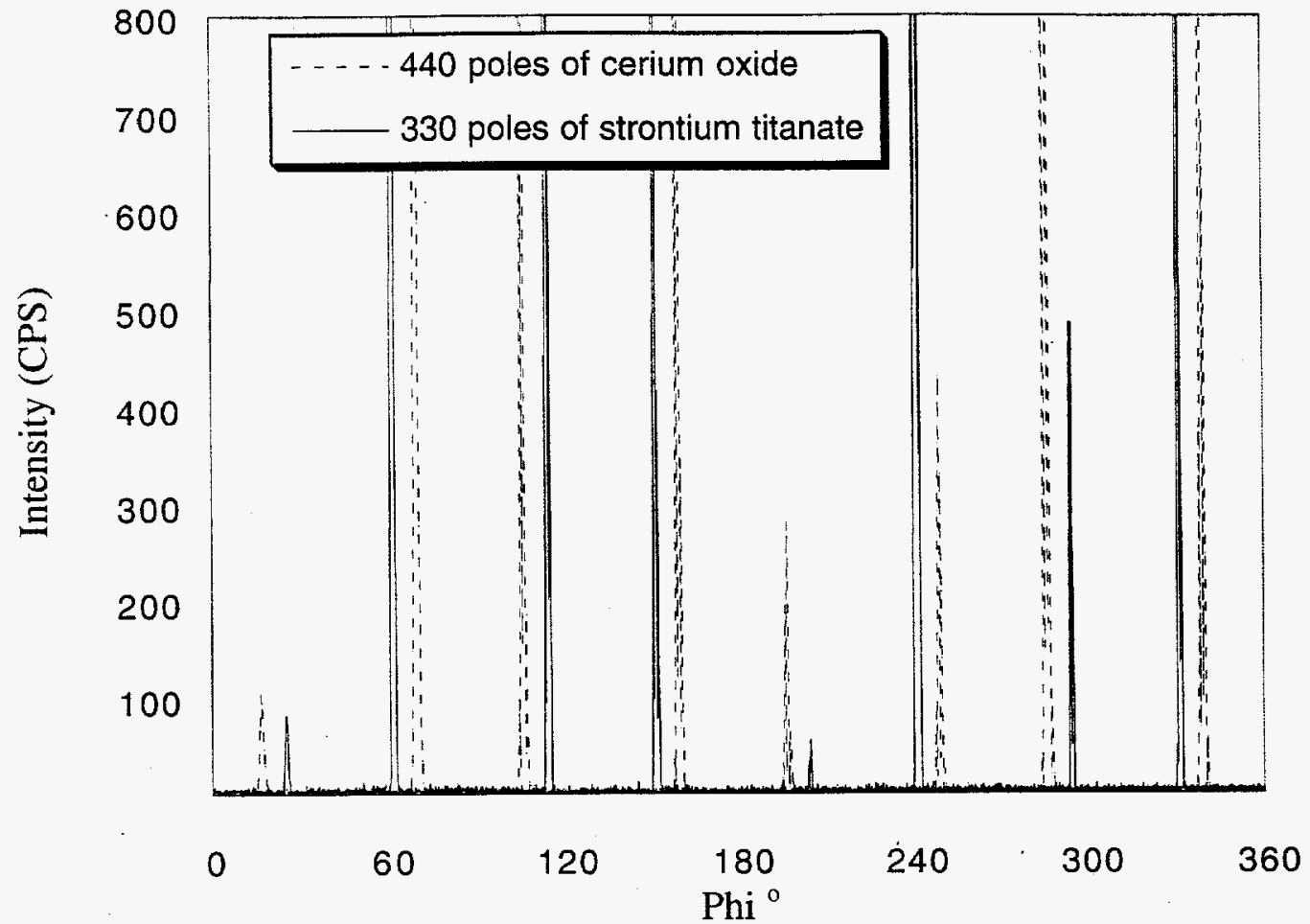

FIG. 2. Phi scan for 440 poles of cerium oxide and 330 poles of strontium titanate

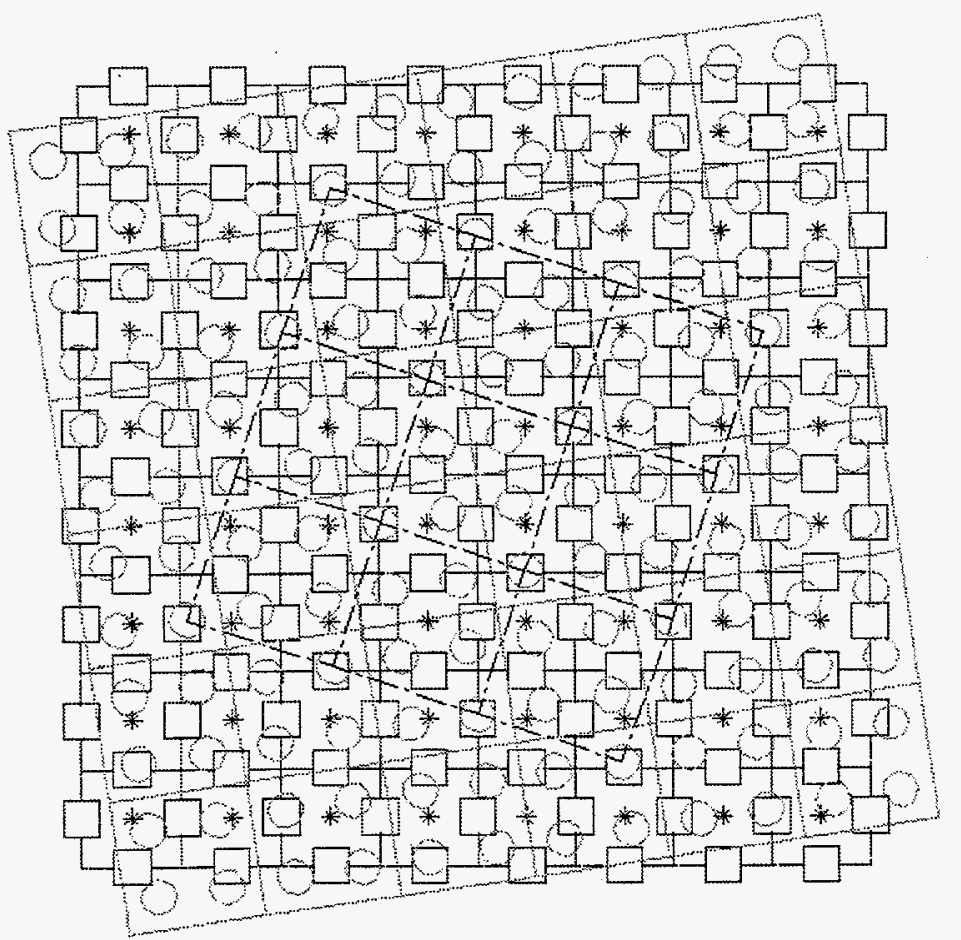

-... Coincident Site

Lattice

* $\quad \mathrm{Ti}$ in $\mathrm{SrTiO}_{3}$ layer

$\square \quad \mathrm{O}$ in $\mathrm{SrTiO}_{3}$ layer

$\mathrm{O}$ in $\mathrm{CeO}_{2}$ layer

FIG. 3. Coincident site lattice showing coincidence of $\Sigma 5$ of cerium oxide with $\Sigma 10$ of strontium titanate. 


\section{SUMMARY}

On r-plane sapphire it is seen that there is an improvement in crystallinity of $\mathrm{CeO}_{2}$ films with deposition temperature. A rotation of $8^{\circ}$ has been observed when cerium oxide films were deposited on strontium titanate.This has been explained by the coincidence of the $\Sigma 10$ boundary of strontium titanate with the $\Sigma 5$ boundary of cerium oxide. We do not believe this rotation has been observed before.

\section{ACKNOWLEDGMENTS}

The author wishes to thank Prof. Susan E. Babcock of the University of Wisconsin-Madison, for taking the time to analyze the coincident site lattice information presented in this paper. The author also wishes to express his gratitude to Eric L. Brosha of the Los Alamos National Laboratory for helping with the phi scans .

\section{REFERENCES}

1. M. E. Hawley, R. J. Houlton, K. N. Springer, C. B. Mombourquette, 1994 Spring Meeting of MRS.

2. D. W. Reagor, K. N. Springer, F. Garzon, M. Hawley, R. J. Houlton, C. Mombourquette and I. D. Raistrick (unpublished). 